DOI: 10.20472/IAC.2017.034.014

\author{
IRENA CHIRU \\ National Intelligence Academy, Romania \\ CRISTINA IVAN \\ National Intelligence Academy, Romania
}

\title{
INNOVATING TRAINIGN PRACTICES IN RISK SOCIETY. ASSESSING HYBRID THREATS WITH MULTICULTURAL (CON)TEXTS
}

\begin{abstract}
:
Today's risk society renders an acute sense that there exists a whole new range of tools of power advanced in the online environment that hybridize both understanding and behavior of the political actors. Therefore, one feels the need to develop an understanding of how such instruments operate, generate threats and destabilize the social fabric of democratic societies. The current paper advances in this context an experimental methodology for training aimed at facilitating the acquisition of skills required in the assessment of hybrid threats. Starting from the premise that (inter)active and experimental learning need to be regarded as fundamentals of successful training, the paper presents the philosophy and the practice of the exercise designed to serve as an interactive training tool for the participants in the Security in the Black Sea Region. Shared Challenges, Sustainable Future" Program. Entitled The new power kit. Policies of attraction, subversion and projection in the Black Sea Region, the exercise embraces the need to bring together practitioners, policymakers and stakeholders from a large variety of national backgrounds being therefore designed for multicultural formats and multi-purpose teams. Its potential for replication has been tested with great success in different formats and professional backgrounds, therefore we assess that with the current methodology it can be tailored and applied not only in the Black Sea context but regardless of the region/country of interest and socio-economic conditions that the trainer might like to apply.
\end{abstract}

\section{Keywords:}

innovative training for risk assessment, gaming in education, fusing context-driven knowledge acquisition

JEL Classification: $123, \mathrm{H} 70$ 